\title{
Characterization of the plutonium-water reaction II: Formation of a binary oxide containing $\mathrm{Pu}(\mathrm{VI})$
}

\author{
Jerry L. Stakebake and D.T. Larson \\ EG\&G Rocky Flats, Inc., Golden, CO 80402 (USA)
}

John M. Haschke

Los Alamos National Laboratory, Los Alamos, NM 87545 (USA)

(Received January 26, 1993; in final form May 26, 1993)

\begin{abstract}
Characterization of products formed by reacting unalloyed plutonium with water vapor at 15 Torr pressure shows that $\mathrm{Pu}_{2} \mathrm{O}_{3}, \mathrm{PuO}_{2}$ and a previously unreported binary oxide containing $\mathrm{Pu}(\mathrm{VI})$ form on the metal between 200 and $350^{\circ} \mathrm{C}$. Although the reaction produces a uniformly adherent product layer with a thickness of about 5 $\mu \mathrm{m}$, localized pits of plutonium hydride cover 15-20\% of the oxide-metal interface beneath the layer. Analytical results show that the non-equilibrium product contains layers of three oxide phases at all temperatures. Cubic $\alpha-\mathrm{Pu}_{2} \mathrm{O}_{3}$ appearing at the metal interface is covered by a layer of dioxide. A third oxide formed at the gas-solid interface is identified by $\mathrm{X}$-ray diffraction and $\mathrm{X}$-ray photoelectron spectroscopy as the mixed-valence phase $\mathrm{Pu}(\mathrm{IV})_{3-x} \mathrm{Pu}(\mathrm{VI})_{x} \mathrm{O}_{6+x}$. Diffraction data suggest that this oxide crystallizes in a fluorite-related $\mathrm{NpH}_{2+\delta}$ or $\mathrm{Sm}_{3} \mathrm{H}_{7}\left(\mathrm{Ca}_{2} \mathrm{YF}_{7}\right)$-type structure. Formation of the higher oxide is supported by $\mathrm{X}$-ray photoelectron spectra, indicating the presence of the $\mathrm{Pu}(\mathrm{VI})$ oxidation state. Evaluation of the results yields an oxide composition corresponding to a value of $x$ near 0.5 . Estimated thermodynamic data suggests that the oxide is a stable phase in the $\mathrm{Pu}-\mathrm{O}$ system; experimental observations show that the product is preserved during exposure to air and ultrahigh vacuum. Although formation of $\mathrm{PuO}_{2.2}$ is expected to be a slow process at low temperatures, reaction of $\mathrm{PuO}_{2}$ with moisture adsorbed on its surface may generate large quantities of hydrogen if dioxide is stored for an extended period.
\end{abstract}

\section{Introduction}

Many early investigations of plutonium reactivity focus on the atmospheric corrosion of the metal and are described in reviews $[1,2]$ that examine the effect of water vapor on the reaction rate. However, little effort has been directed toward achieving a basic understanding of the plutonium-water reaction. Since prior studies involving water vapor are primarily one dimensional with emphasis on the kinetic effect of temperature and do not include thorough characterization of the products, little indication is given about the complexity of $\mathrm{Pu}+\mathrm{H}_{2} \mathrm{O}$ [3-6]. The first evidence that hydrolysis does not follow a simple reaction sequence to form $\mathrm{PuH}_{2}$ and $\mathrm{PuO}_{2}$ was reported by Haschke et al. [7], who investigated the reaction of plutonium with liquid water at $23^{\circ} \mathrm{C}$. The corrosion process forms a series of oxide hydrides and mixed-valence oxides. These findings point to a lack of understanding of the plutonium-water reaction and suggest that the plutonium-oxygen phase diagram is similar to that for praseodymium-oxygen [8]. These results emphasize the need for an extensive multidimensional investigation of the reaction between plutonium and water vapor.

Whereas kinetic results for the reaction between water vapor and the $\mathrm{Pu}-1 \mathrm{wt} . \% \mathrm{Ga}$ alloy are well behaved [9], data for hydrolysis of unalloyed metal in the 50-350 ${ }^{\circ} \mathrm{C}$ range are complex. A large decrease is observed in the reaction rate as the temperature increases from 110 to $200^{\circ} \mathrm{C}[10]$. Such behavior frequently accompanies temperature-induced changes in reaction mechanism arising from control by a new rate-determining step or from occurrence of a different chemical reaction. Kinetic data are reported for the $200-350{ }^{\circ} \mathrm{C}$ range [11], but product characterization is incomplete. The present study was initiated to define the $\mathrm{Pu}+\mathrm{H}_{2} \mathrm{O}$ reaction in the range of interest and results of this effort are described in this report.

\section{Experimental details}

Samples used for identifying products of the $\mathrm{Pu}+\mathrm{H}_{2} \mathrm{O}$ reaction were partially oxidized metal coupons that had 
been reacted with water vapor during the kinetic experiments. The hydrolysis rates were measured gravimetrically with a Cahn electrobalance mounted in an experimental system described previously [9]. Metal samples used in the kinetic studies were cut from plutonium rods of $10 \mathrm{~mm}$ diameter having a total metallic impurity content of $102 \mathrm{ppm}$, excluding an undetermined amount of Am which accumulates as a product of ${ }^{241} \mathrm{Pu}$ decay. Water vapor was provided by a liquid source attached to the gas inlet manifold of the balance system. The source consisted of $200 \mathrm{ml}$ of distilled water in a stainless steel vessel. Air was removed from the source by a series of three degassing cycles in which the water was frozen, exposed to $10^{-6}$ Torr vacuum and then melted.

Prior to being placed in the microbalance system, each cylindrical metal sample (geometric surface area, $1.31 \mathrm{~cm}^{2}$ ) was polished in air with 400 grit silicon carbide paper to remove the oxide surface layer. The system was evacuated for about $1 \mathrm{~h}$ to achieve a residual pressure in the $10^{-6}$ Torr range, but this procedure did not remove all adsorbed water from the chamber. The sample was heated to the desired temperature, and water vapor was introduced at a constant pressure of 15 Torr. After rate measurements were complete, the specimen was removed from the microbalance chamber and transported under an air atmosphere to various locations for analyses. Products were characterized using metallography, X-ray diffraction (XRD), X-ray photoelectron spectroscopy (XPS) and wavelength-dispersive spectroscopy (WDS) with a scanning electron microprobe. The X-ray photoelectron spectrum was also obtained for the hydrolysis product formed on the 1 wt.\% Ga alloy at $250^{\circ} \mathrm{C}$.

The test matrix for this investigation was designed to provide information on the nature of the plutonium-water reaction at an isobaric condition over the $200-350^{\circ} \mathrm{C}$ range. This temperature regime is of interest because it spans a well-behaved segment of the Arrhenius curve for $\mathrm{Pu}+\mathrm{H}_{2} \mathrm{O}$ following a sharp kinetic anomaly. Analysis of products obtained during kinetic studies guaranteed that the specimens were representative.

\section{Results}

\subsection{Reaction kinetics}

The hydrolysis kinetics of unalloyed plutonium differ from those for the $1 \mathrm{wt} \% \mathrm{Ga}$ alloy. The reaction of the alloy proceeds through three sequential stages at all temperatures over the $150-350{ }^{\circ} \mathrm{C}$ range [9]. The initial parabolic stage arising from progressive buildup of a product diffusion layer on the metal surface is followed by a linear or constant-rate stage in which the rate is controlled by diffusion of reactant species through a layer of constant average thickness maintained by continuous spallation of product. After a period of several hours, this two-step "paralinear" process is followed by acceleration to a rapid linear stage in which the protective layer is apparently absent and the rate is interface controlled [9]. In contrast, the reaction of unalloyed metal shows paralinear kinetics only above $200^{\circ} \mathrm{C}$. This behavior is shown by the extent of the reaction-time curves in Fig. 1. The linear rate of the second stage is a factor of 10 greater than that for the alloy. The reaction proceeds to completion without accelerating to a rapid third stage.

Although hydrolysis of unalloyed metal is well behaved with temperature over the $200-350^{\circ} \mathrm{C}$ range, the complexity of the reaction is shown by Arrhenius results for a somewhat wider temperature range in Fig. 2 [11]. The linear rate constant $k$ decreases by more than fiftyfold as the temperature increases from 150 to 200 ${ }^{\circ} \mathrm{C}$. The activation energy measured for the linear stage at higher temperatures is $13 \mathrm{kcal} \mathrm{mol}^{-1}$ and agrees well with the $15 \mathrm{kcal} \mathrm{mol}^{-1}$ value obtained for the linear stage of the $\mathrm{Pu}+\mathrm{O}_{2}$ reaction [12]. The similarities of paralinear kinetics and comparable $E_{\mathrm{a}}$ values for the reactions of water vapor and oxygen suggest that the rate-controlling processes at high temperature involve diffusion of similar chemical species through the product layer on the metal surface.

The origins of the kinetic differences between alloyed and unalloyed plutonium and of the rate anomaly observed for unalloyed plutonium may be related to the products of reaction. Since the products formed on unalloyed metal were not characterized in the earlier study [9], their identification may provide insight into the kinetics of the $\mathrm{Pu}+\mathrm{H}_{2} \mathrm{O}$ reaction.

\subsection{Product characterization}

\subsubsection{Metallography}

Metallographic analyses were performed on samples of product-coated metal obtained at 250 and $350^{\circ} \mathrm{C}$. Specimens were prepared by polishing one edge to expose a cross-section of the product layers for analysis. At both temperatures, photomicrographic data show two modes of reaction: a pitting type of attack and formation of a thin uniform product layer. Figure 3 shows a $200 \times$ photomicrograph of a sample obtained at $250^{\circ} \mathrm{C}$. The uniform product layer is quite thin (on the order of $5 \mu \mathrm{m}$ ) owing to spallation. In contrast, the uniform layer present during the second stage of the alloy-water reaction approaches $0.1 \mathrm{~mm}$ in thickness [9]. As seen in Fig. 3, a large fraction (15-20\%) of the interface between the uniform layer and the metal is covered by localized pits that are $50-75 \mu \mathrm{m}$ deep. An $800 \times$ magnification of the pitted area in Fig. 4 suggests that two different products are present. 


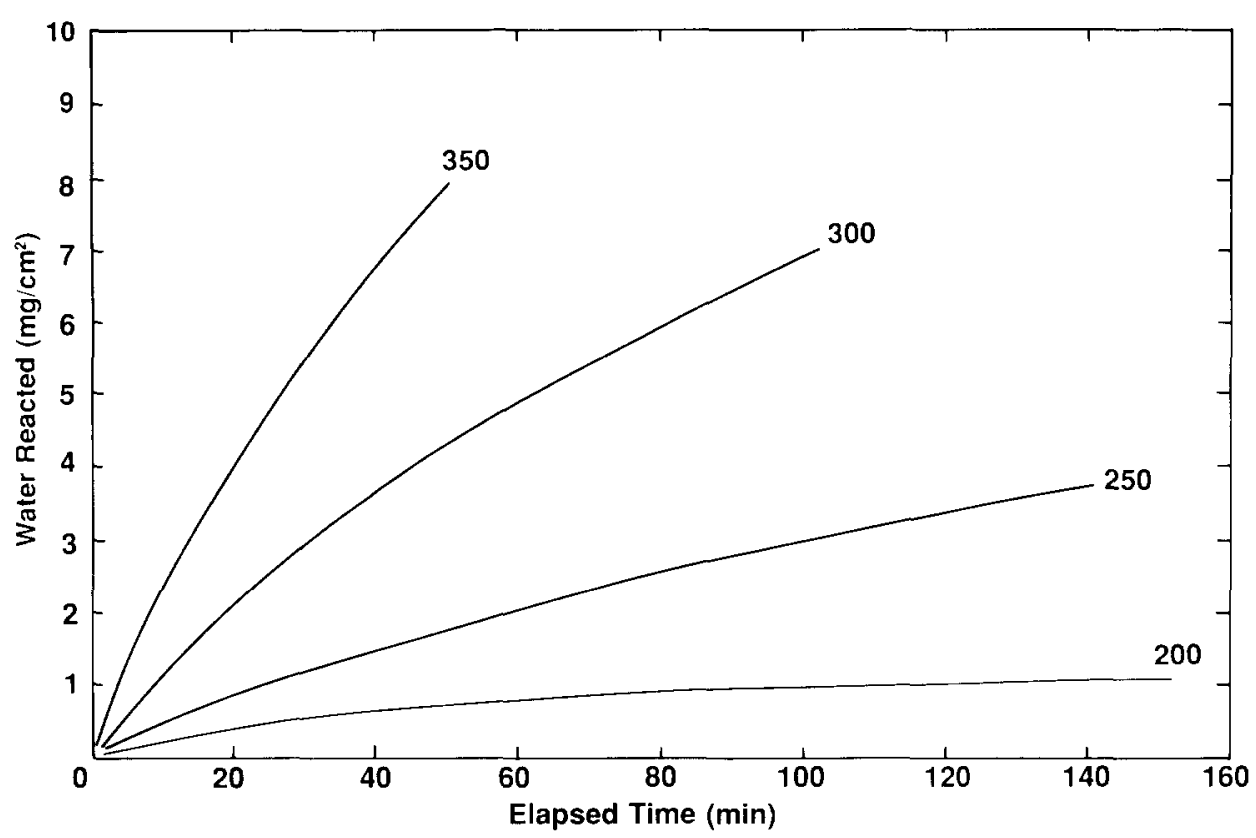

Fig. 1. Time dependence of mass gain during the reaction of unalloyed plutonium with water vapor at 15 Torr pressure and temperatures in the $200-350{ }^{\circ} \mathrm{C}$ range.

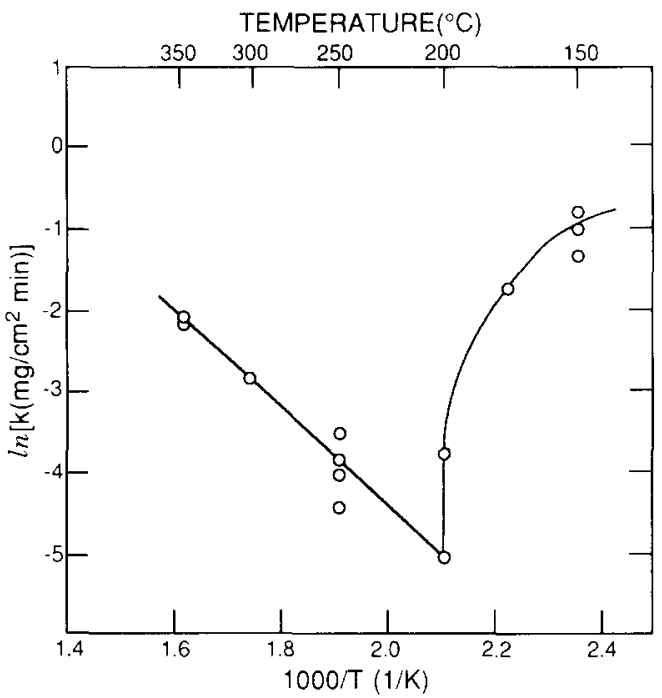

Fig. 2. The effect of temperature on the linear hydrolysis rate of unalloyed plutonium at 15 Torr water vapor pressure.

\subsubsection{Wavelength-dispersive spectroscopy}

The metallographic observations are confirmed by WDS analysis of the pitted area shown in Fig. 4. The oxygen map in Fig. 5 shows that the product concentrated at the metal interface contains no oxygen. This region is assumed to be plutonium hydride because the presence of all possible elements other than hydrogen is eliminated by WDS analysis. The remainder of the material in the reaction pit and the uniform product layer is oxide. Hydride is detected only in pitted regions beneath the uniform layer. Similar results are observed in samples obtained at $350{ }^{\circ} \mathrm{C}$.

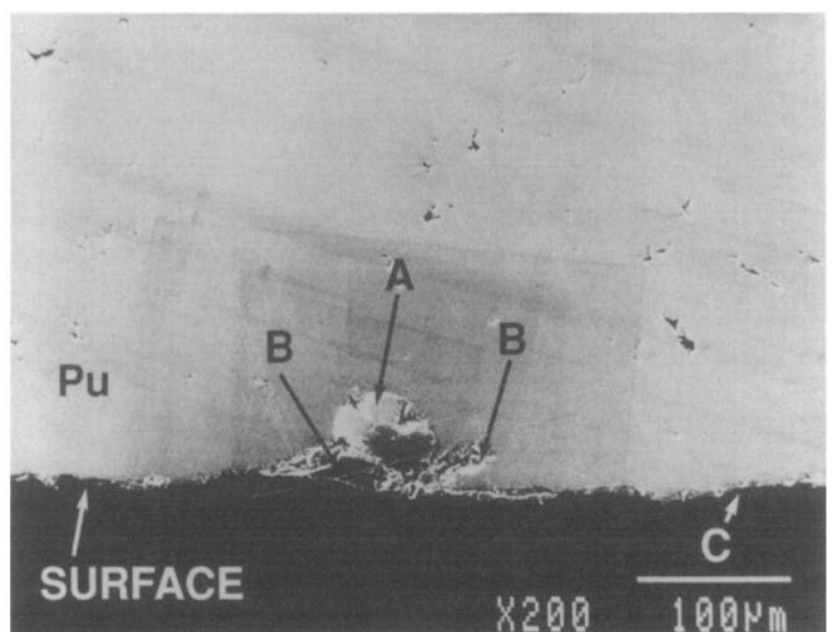

Fig. 3. Photomicrograph of a cross-sectioned sample obtained by reacting unalloyed plutonium with water vapor at $250{ }^{\circ} \mathrm{C}$. The reaction forms a uniform product layer $(C)$ and produces pits (A and B) covering 15-20\% of the surface. (Magnification, $200 \times$.)

Specific identification of the oxide products formed at 250 and $350^{\circ} \mathrm{C}$ is not possible with the WDS technique. However, comparison of intensity ratios for the oxygen and plutonium X-ray fluorescence spectra shows that the oxygen concentration in the layer produced at 350 ${ }^{\circ} \mathrm{C}$ is about $22 \%$ less than in the layer formed at 250 ${ }^{\circ} \mathrm{C}$. Although these results are inconclusive, they are consistent with XPS and XRD data presented in the following sections. 


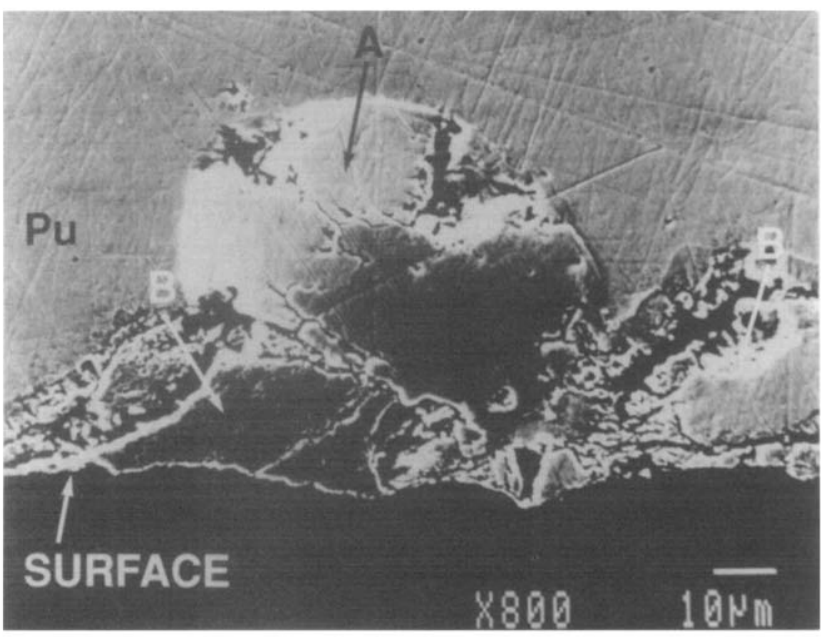

Fig. 4. Photomicrograph of a reaction pit formed during reaction of unalloyed plutonium with water vapor at $250^{\circ} \mathrm{C}$. Two products, $\mathrm{A}$ and $\mathrm{B}$, are suggested. (Magnification $800 \times$.)

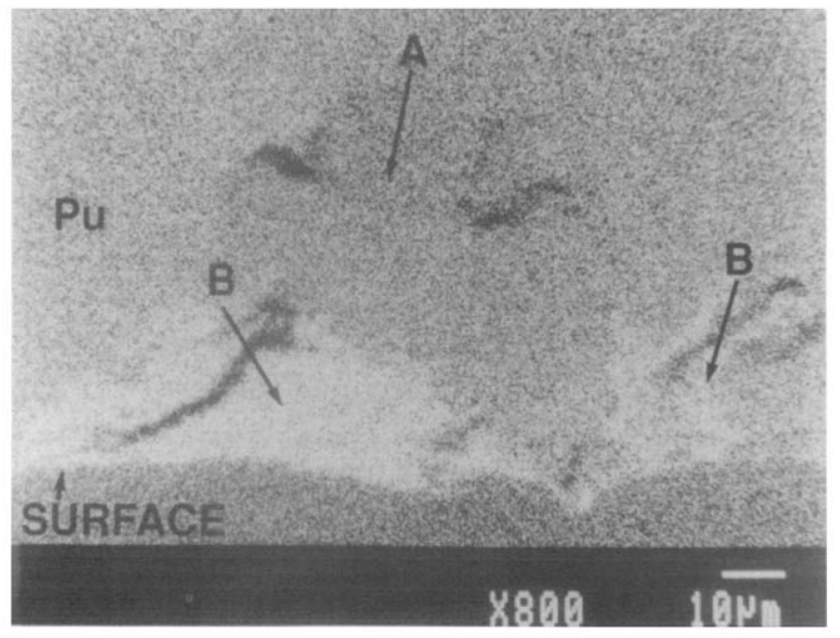

Fig. 5. Oxygen concentration map of the pitted area shown in Fig. 4. Products include plutonium oxide (B) in the surface region of the pit and an oxygen-free region (A) identified as plutonium hydride at the metal interface. (Magnification $800 \times$.)

\subsubsection{X-ray photoelectron spectroscopy}

XPS analyses were conducted with specimens that were carefully handled to avoid surface contamination. Traces of hydroxide and carbonate species were unavoidably introduced by exposing samples to air during transfer from the microbalance to the spectrometer. Prior to placement in the spectrometer, samples were cleaned with a soft brush to remove loose oxide and other particles. The XPS spectrometer is described in an earlier report [13]. Core-electron $\mathrm{Pu} 4 \mathrm{f}_{7 / 2}$ spectra obtained for three specimens after reaction with water vapor at different temperatures are shown in Fig. 6. Binding energies for $\mathrm{PuO}_{2}(426.3 \mathrm{eV})$ and $\mathrm{Pu}_{2} \mathrm{O}_{3}(424.8$ $\mathrm{eV})$ are marked in the figure [13, 14].

The specimen obtained at $60{ }^{\circ} \mathrm{C}$ was covered by a product with the green color characteristic of $\mathrm{PuO}_{2}$.

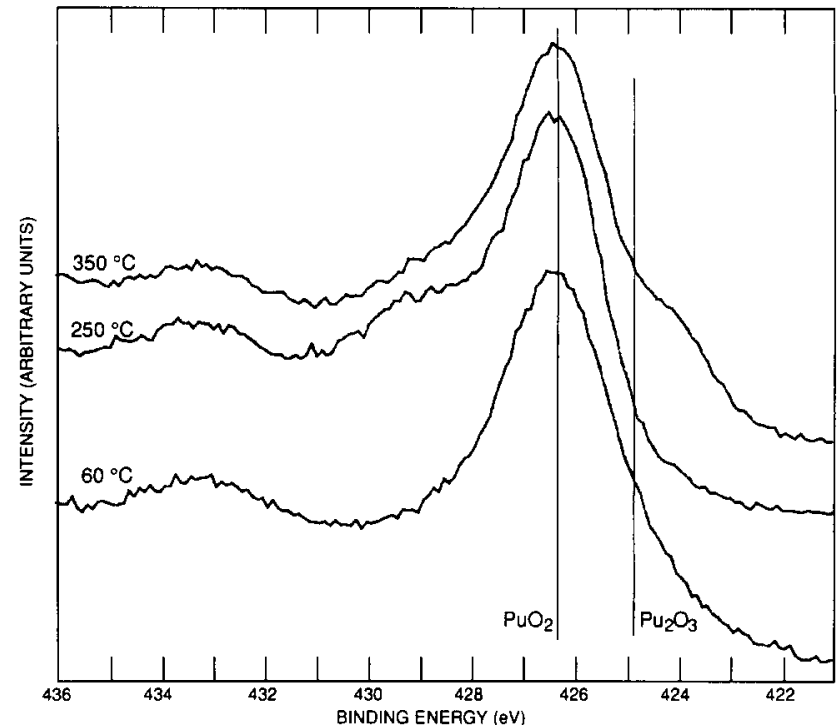

Fig. 6. Fig. 6. X-ray photoelectron $P u 4 f_{7 / 2}$ spectra of the products formed by reacting unalloyed plutonium with water vapor at 15 Torr pressure and 60,250 and $350^{\circ} \mathrm{C}$.

The XPS results for this sample in Fig. 6 confirm this conclusion, but the original spectrum indicated the occurrence of a "charge-up" problem. All peaks were uniformly shifted to a higher binding energy. The data were corrected by referencing to the $O 1$ s energy level at $530.1 \mathrm{eV}$ for $\mathrm{O}^{2-}$ in a dioxide lattice [14]. After correction by subtracting $8.4 \mathrm{eV}$ from the original energy scale, the spectrum with its shake-up peak at about $433 \mathrm{eV}$ shows that the surface product is $\mathrm{PuO}_{2}$.

Unlike the sample obtained at a low temperature, the specimens prepared at $250{ }^{\circ} \mathrm{C}$ were covered by a black product characteristic of a non-stoichiometric or defect phase. Spectra for these samples do not have peak shifts like those associated with "charge-up". The $\mathrm{O} 1 \mathrm{~s}$ peak appears at $530.1 \mathrm{eV}$. As shown in Fig. 6, the hydrolysis product obtained at $250{ }^{\circ} \mathrm{C}$ has the $\mathrm{Pu}$ $4 \mathrm{f}_{7 / 2}$ peak characteristic of $\mathrm{PuO}_{2}$. However, a new unidentified peak (shoulder) appears at $429.0 \pm 0.4 \mathrm{eV}$ in the spectra of all specimens prepared at $250{ }^{\circ} \mathrm{C}$ including that for $1 \mathrm{wt} \% \mathrm{Ga}$ alloy. After exposure to vacuum for 3 days, the shoulder decreased in relative intensity but was still evident. This observation suggests that the chemical system composed of product layer and underlying metal is not at thermodynamic equilibrium and continues to react at a slow rate or that the surface is contaminated with a volatile material that is slowly removed in vacuum.

The $\mathrm{Pu} 4 \mathrm{f}_{7 / 2}$ spectrum for a similar black product obtained at $350{ }^{\circ} \mathrm{C}$ shows a mixture of $\mathrm{PuO}_{2}$ and $\mathrm{Pu}_{2} \mathrm{O}_{3}$. As shown by the spectrum in Fig. 6, the presence of trivalent oxide is evidenced by a low binding energy shoulder with its centroid at $423.9 \mathrm{eV}$. Although the binding energy is somewhat lower than expected, the 
shoulder is attributed to $\mathrm{Pu}_{2} \mathrm{O}_{3}$ on the basis of the results of a test in which a $\mathrm{Pu}_{2} \mathrm{O}_{3}$ surface film was oxidized to $\mathrm{PuO}_{2}$ in oxygen. The $\mathrm{Pu} 4 \mathrm{f}_{7 / 2}$ spectrum for that product consisted of the characteristic $\mathrm{PuO}_{2}$ peak plus a low intensity shoulder arising from residual $\mathrm{Pu}_{2} \mathrm{O}_{3}$. As with the hydrolysis product, the centroid of that shoulder was also shifted to a lower binding energy than for pure trivalent oxide.

Spectra for $350^{\circ} \mathrm{C}$ samples also have a small shoulder at $429.0 \mathrm{eV}$. Although this feature is not as predominant as for samples obtained at $250^{\circ} \mathrm{C}$, the presence of the new peak is clearly shown by comparing a smoothed (11-point cubic) spectrum for the $350{ }^{\circ} \mathrm{C}$ product with that for the $60{ }^{\circ} \mathrm{C}$ reference specimen in Fig. 7. Data for additional hydrolysis samples show that the $429 \mathrm{eV}$ shoulder is consistently present in products formed at $350{ }^{\circ} \mathrm{C}$, but absent from those obtained at $200^{\circ} \mathrm{C}$.

A broad peak (shoulder) with a centroid near 532 $\mathrm{eV}$ is observed near the oxide $\mathrm{O} 1 \mathrm{~s}$ peak for all samples. The shoulder is small relative to the peak at $530.1 \mathrm{eV}$ and absent from spectra for oxide surfaces prepared by in situ reaction of $\mathrm{Pu}$ with $\mathrm{O}_{2}$ in the XPS system, but is consistently present for oxide surfaces after exposure to air. The appearance of the shoulder does not correlate with the presence of the peak at $429 \mathrm{eV}$. The $\mathrm{O} 1 \mathrm{~s}$ binding energies for $\mathrm{OH}$-containing species are generally higher than those for oxides [15] and the broad peak may result from the combined effect of $\mathrm{HOH}, \mathrm{ROH}, \mathrm{RCOOH}$ etc. However, the peak is probably due to water adsorbed in several configurations on the oxide surface.

The possible reasons for the appearance of the new peak near $429 \mathrm{eV}$ include (1) the presence of an unknown impurity, (2) contamination by $\mathrm{PuF}_{4}$, (3) the occurrence of heterogeneous "charge-up" or (4) the formation of

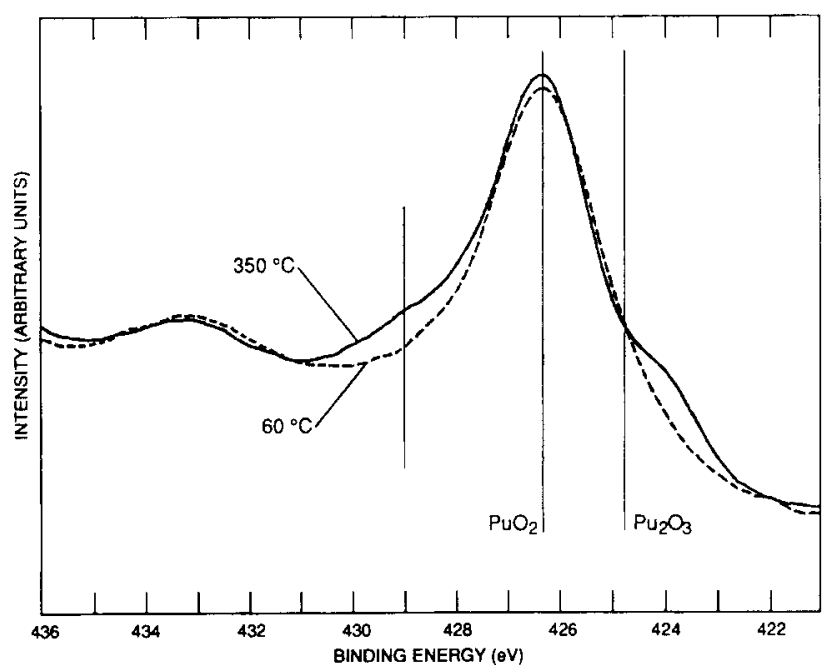

Fig. 7. Comparison of $\mathrm{X}$-ray photoelectron $\mathrm{Pu} 4 \mathrm{f}_{7 / 2}$ spectra (smoothed 11 point-cubic) for the plutonium hydrolysis products formed at 60 and $350{ }^{\circ} \mathrm{C}$. an oxide having an oxidation state higher than $\mathrm{Pu}(\mathrm{IV})$. The possibility of an unknown impurity is addressed by simultaneously examining the $\mathrm{Pu} 4 \mathrm{f}_{7 / 2}$ and the $\mathrm{Pu}$ $4 \mathrm{f}_{5 / 2}$ spectra shown in Fig. 8. A similar high binding energy shoulder observed for the $\frac{5}{2}$ level shows that the peak is associated with a compound of plutonium. $\mathrm{PuF}_{4}$ is the only known compound with $\mathrm{Pu}$ 4f binding energies near the new peaks [16], but its absence is demonstrated by failure to observe the $\mathrm{X}$-ray photoelectron spectrum for fluorine.

Since charge-up problems were encountered with the hydrolysis product formed at $60^{\circ} \mathrm{C}$, the possible effect of heterogeneous charge-up must be considered. This type of charge-up occurs when insulating particles containing an element are embedded in a conducting matrix having the element in the same chemical state. The binding energies for the element in the insulated phase are shifted relative to that of the conducting phase and a doubled X-ray photoelectron spectrum is observed. To determine whether the spectrum for the $250{ }^{\circ} \mathrm{C}$ specimen contains charge-up artifacts, the kinetic energy of the $81 \mathrm{eV}$ plutonium Auger peak induced in the sample with an $\mathrm{Al} \mathrm{K} \alpha \mathrm{X}$-ray source was compared with that induced in a thin plutonium oxide film with negligible possibility of charging. As shown in Fig. 9, the spectra for the sample and for a film $200 \AA$ thick on the metal are identical and suggest that the new peak is not the result of heterogeneous charge-up.

The remaining possibility is that the new XPS peak originates from an oxide product containing a higher oxidation state of plutonium. The binding energy is strongly dependent on oxidation state and data for $\mathrm{Pu}(0)$ as metal and for $\mathrm{Pu}(\mathrm{III})$ and $\mathrm{Pu}(\mathrm{IV})$ as oxides $[13,14,16-18]$ in Fig. 10(a) are fitted reasonably well by a straight line. The graph indicates that the new

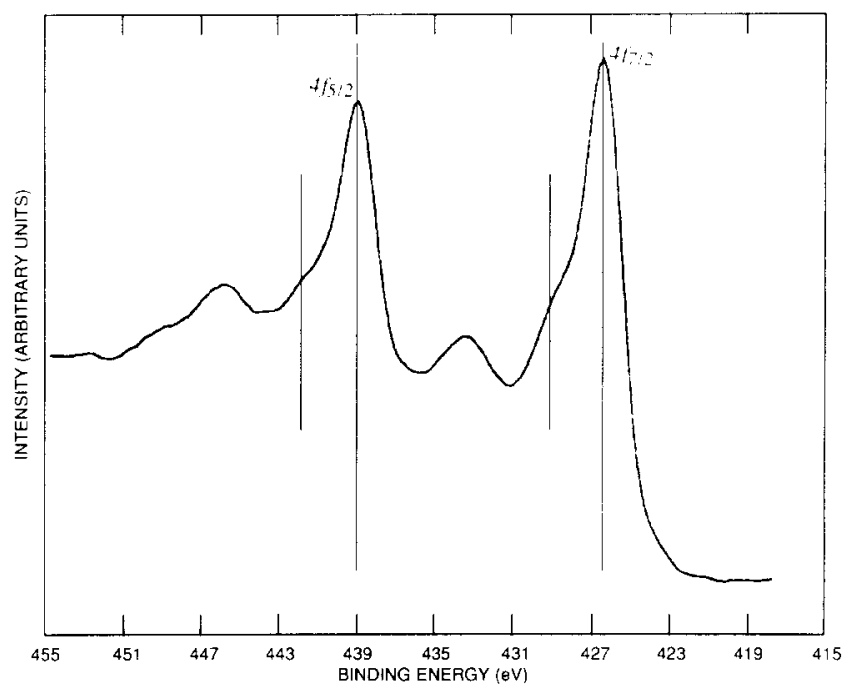

Fig. 8. X-ray photoelectron $\mathrm{Pu} 4 \mathrm{f}$ spectrum (smoothed 11-point cubic) of the plutonium hydrolysis product formed at $250^{\circ} \mathrm{C}$. 


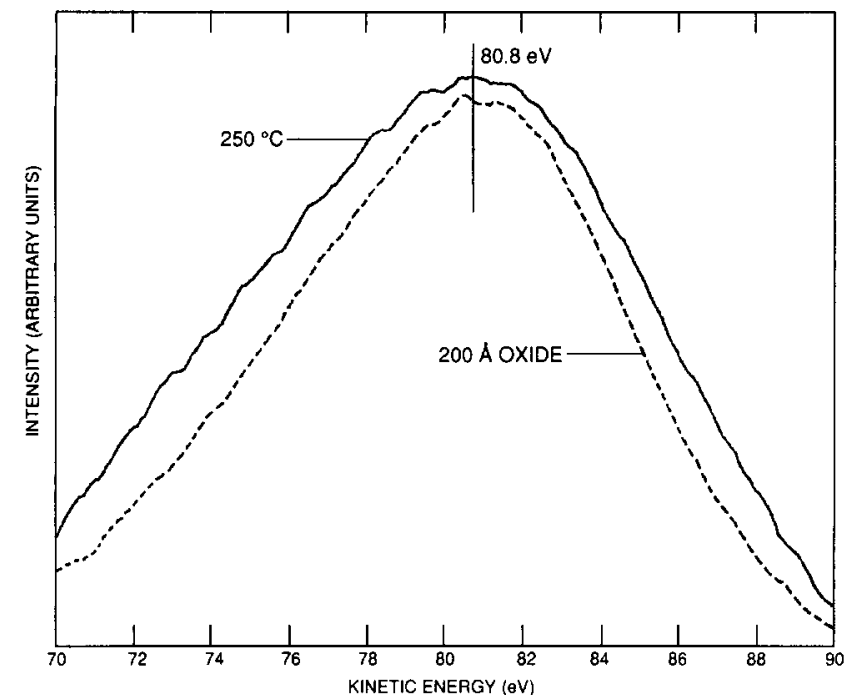

Fig. 9. Comparison of the Pu Auger energy for the hydrolysis product formed on unalloyed metal at $250{ }^{\circ} \mathrm{C}$ with that for a thin (about $200 \AA$ ) oxide film on the metal. The spectra were obtained using $\mathrm{Al} \mathrm{K} \alpha \mathrm{X}$-rays and were treated by non-linear background subtraction and 11-point cubic smoothing.

peak at $429.0 \mathrm{eV}$ corresponds to a $\mathrm{Pu}(\mathrm{VI})$ or $\mathrm{Pu}(\mathrm{VII})$ oxidation state. Since the binding energy is sensitive to other factors such as chemical environment, structure and Madelung effects, the validity of using a linear correlation to predict oxidation state is evaluated using XPS data for uranium oxides [19-22]. The database includes binding energies for $\mathrm{UO}_{2}, \mathrm{UO}_{3}$ and $\mathrm{U}_{3} \mathrm{O}_{8}$, a mixed-valence oxide formulated as $\mathrm{U}(\mathrm{IV}) \mathrm{U}(\mathrm{VI})_{2} \mathrm{O}_{8}$ and having resolved XPS peaks assigned to the two oxidation states $[20,21]$. The graph of $U 4 f_{7 / 2}$ binding energy $v s$. oxidation state is presented in Fig. 10(b). The correlation and uncertainty are similar to those observed for plutonium and support the validity of the extrapolation in Fig. 10(a). Since the existence of heptavalent plutonium is precluded by chemical considerations, the higher oxidation state is identified as $\mathrm{Pu}(\mathrm{VI})$.

\subsection{4. $X$-ray diffraction}

$\mathrm{XRD}$ analyses were performed on hydrolysis samples with a high resolution powder diffractometer using $\mathrm{Cu}$ $\mathrm{K} \alpha_{1}$ radiation. Reaction products remained on the metal substrates that were wrapped in a thin polyester film and mounted directly in the diffractometer for analysis of their surfaces. Samples prepared at 250 and $350^{\circ} \mathrm{C}$ were analyzed to determine $d$ values and relative intensities. Data for closely spaced reflections were resolved using manual procedures.

The diffraction data for the hydrolysis product obtained at $250{ }^{\circ} \mathrm{C}$ indicate that it is a mixture of phases. Observed $d$ values and relative intensities listed in Table 1 are representative of the data obtained by analysis
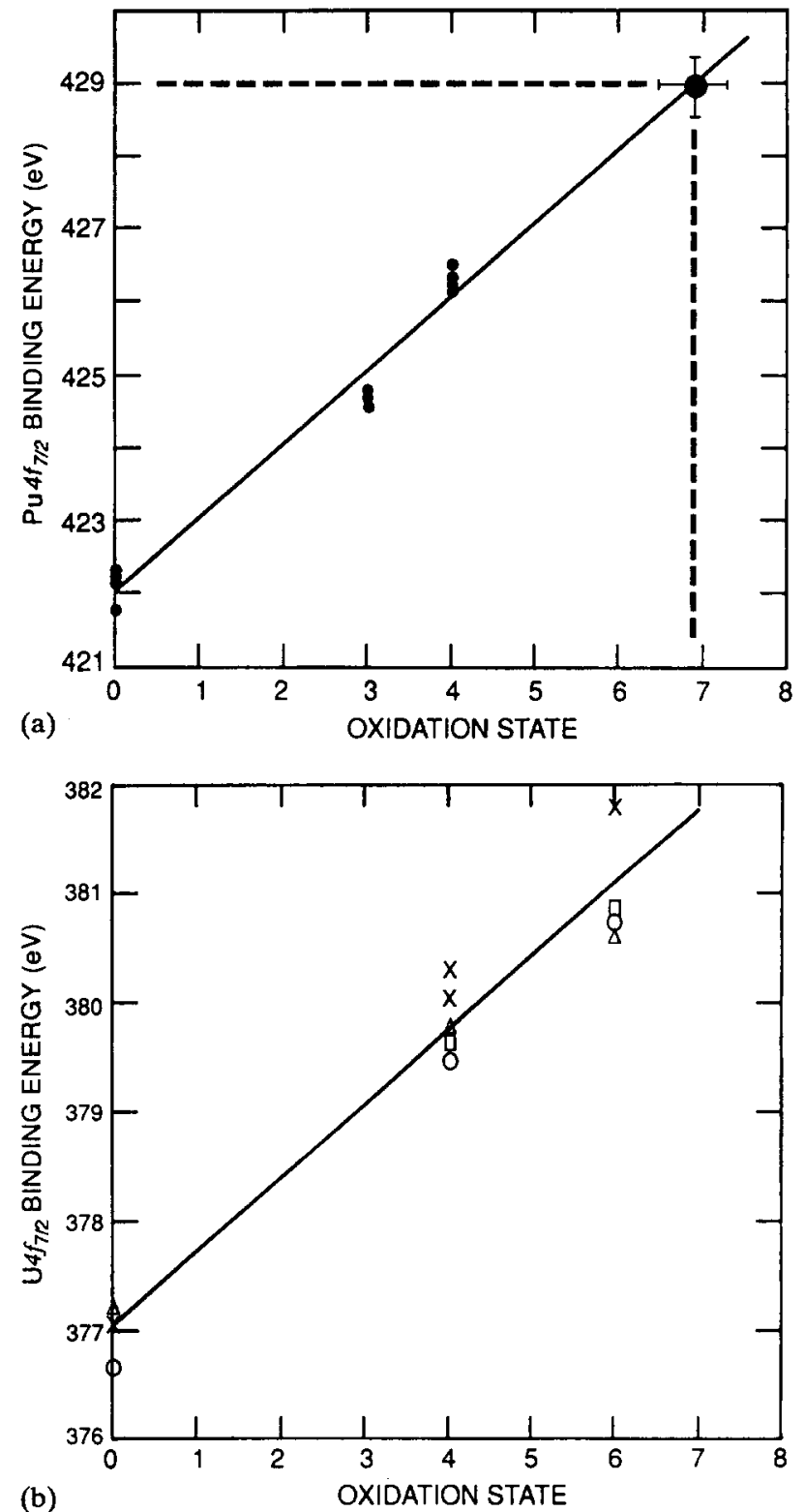

Fig. 10. Correlation of the XPS $4 \mathrm{f}_{7 / 2}$ binding energy with oxidation state: (a) binding energy-oxidation state values for plutonium [13-16]; (b) binding energy-oxidation state results for uranium: $\times,[17] ; O,[18] ; \triangle,[19] ; \square,[20]$.

of four independent samples. However, the spectrum for one of the specimens contained an additional set of weak reflections. The presence of f.c.c. $\mathrm{PuO}_{2}$ is readily discernible and approximately half the reflections are assignable to the $F m 3 m$ phase. The derived lattice parameter $\left(a_{0}=5.398(3) \AA\right)$ is in excellent agreement with the value $(5.397(1) \AA)$ given in the literature for the dioxide [23].

Assignment of the remaining diffraction lines is more difficult. The appearance of these reflections as shoulders on the $\mathrm{PuO}_{2}$ peaks suggests the presence of another f.c.c. phase. A second cubic pattern is readily attributed 
TABLE 1. Powder X-ray diffraction data for the product layer formed by the $\mathrm{Pu}+\mathrm{H}_{2} \mathrm{O}$ reaction at $250{ }^{\circ} \mathrm{C}$

\begin{tabular}{|c|c|c|c|c|c|c|c|}
\hline \multicolumn{2}{|c|}{ Observed reflections } & \multicolumn{2}{|c|}{$\mathrm{PuO}_{2}$ phase } & \multicolumn{2}{|c|}{$\mathrm{NpH}_{2+\delta}$ type } & \multicolumn{2}{|c|}{$\mathrm{Sm}_{3} \mathrm{H}_{7}$ type } \\
\hline $\begin{array}{l}d_{\text {obs }} \\
(\AA)\end{array}$ & $\begin{array}{l}I / I_{0} \\
(\%)\end{array}$ & $h k l$ & $\begin{array}{l}d_{\text {calc }} \\
(\AA)\end{array}$ & $h k l$ & $\begin{array}{l}d_{\text {calc }} \\
(\AA)\end{array}$ & $h k l$ & $\begin{array}{l}d_{\text {calc }} \\
(\AA)\end{array}$ \\
\hline 3.111 & 100 & 111 & 3.116 & - & - & - & - \\
\hline 3.089 & 20 & - & - & 112 & 3.088 & 101 & 3.104 \\
\hline 2.698 & 25 & 200 & 2.699 & 200 & 2.681 & {$\left[\begin{array}{lll}0 & 0 & 2 \\
1 & 1 & 0\end{array}\right.$} & $\begin{array}{l}2.711 \\
2.676\end{array}$ \\
\hline 1.907 & 90 & 220 & 1.908 & - & - & 112 & 1.905 \\
\hline 1.895 & 15 & - & - & 220 & 1.895 & 200 & 1.892 \\
\hline 1.628 & 60 & 311 & 1.628 & - & - & 103 & 1.631 \\
\hline 1.617 & 10 & - & - & 312 & 1.616 & 211 & 1.616 \\
\hline 1.557 & 10 & 222 & 1.558 & - & - & - & - \\
\hline 1.547 & 12 & - & - & 224 & 1.544 & 202 & 1.552 \\
\hline 1.350 & 5 & 400 & 1.350 & - & - & 004 & 1.356 \\
\hline 1.238 & 20 & 331 & 1.238 & - & - & 213 & 1.236 \\
\hline 1.230 & 18 & - & - & $\left\{\begin{array}{lll}3 & 3 & 2 \\
3 & 1 & 6\end{array}\right.$ & $\begin{array}{l}1.236 \\
1.226\end{array}$ & $\begin{array}{lll}30 & 0 & 1\end{array}$ & 1.229 \\
\hline 1.207 & 15 & 420 & 1.207 & - & - & 114 & 1.209 \\
\hline 1.200 & 5 & - & - & $\left\{\begin{array}{lll}4 & 2 & 0 \\
4 & 0 & 4\end{array}\right.$ & $\begin{array}{l}1.201 \\
1.197\end{array}$ & $\left\{\begin{array}{lll}2 & 2 & 0 \\
3 & 1 & 0\end{array}\right.$ & $\begin{array}{l}1.200 \\
1.197\end{array}$ \\
\hline 1.102 & 12 & 422 & 1.102 & - & - & 204 & 1.102 \\
\hline 1.095 & 5 & - & - & 424 & 1.093 & 312 & 1.095 \\
\hline 1.038 & 9 & 333 & 1.039 & - & - & - & - \\
\hline 1.032 & 3 & - & - & $\left\{\begin{array}{lll}3 & 3 & 6 \\
5 & 1 & 2\end{array}\right.$ & $\begin{array}{l}1.030 \\
1.032\end{array}$ & 321 & 1.031 \\
\hline
\end{tabular}

to the hydride identified in pitted regions of the metal surface, but this assignment is not supported by experimental observations. The calculated lattice parameter $\left(a_{0}=5.364(3) \AA\right)$ is significantly larger than that $\left(a_{0}=5.359(1) \AA\right)$ reported for $\mathrm{PuH}_{2.0}[23]$ and $\mathrm{a}_{0}$ for the non-stoichiometric hydride decreases regularly with increasing composition to a minimum value $\left(a_{0}=5.34(1)\right.$ $\AA)$ at $\mathrm{PuH}_{2.7}[24]$. The observed diffraction spectrum is inconsistent with $F m 3 m$ symmetry because $h 00$ reflections are systematically absent. Examination of the 200 and 400 lines for the dioxide reveals no evidence for multiplets. Furthermore, X-ray penetration of the thick oxide layer covering the corrosion pits is doubtful. Although the diffraction pattern for hydride might be anticipated, results show that the unassigned reflections are not associated with hydride.

$\mathrm{X}$-ray data indicate that the product formed by the $\mathrm{Pu}+\mathrm{H}_{2} \mathrm{O}$ reaction at $250{ }^{\circ} \mathrm{C}$ is a mixture containing a higher oxide of plutonium in addition to the dioxide. The close correspondence of the unassigned diffraction lines to the reflections for $\mathrm{PuO}_{2}$ suggest that the phase is structurally related to fluorite; the systematic absence of reflections suggests that the phase crystallizes in a lower symmetry than $F m 3 m$. Therefore, possible model structures included those for superstoichiometric $\mathrm{CaF}_{2}$ - related systems that might be formed by substitution of $\mathrm{Pu}(\mathrm{VI})$ for $\mathrm{Pu}(\mathrm{IV})$ in the dioxide lattice. As shown in Table 1 , the additional reflections are assignable to two tetragonal systems derived from fluorite. In one case, the data are indexed on a unit cell based on the structure of non-stoichiometric $\mathrm{NpH}_{2+\delta}$ [25]. The lattice parameters derived from the assignment are $a=5.362(2)$ $\AA$ and $c=10.721(8) \AA$. The pattern is also assigned to an $\mathrm{Sm}_{3} \mathrm{H}_{7}$-type [26] or $\mathrm{Ca}_{2} \mathrm{YF}_{7}$-type [27] structure having $a=3.785(5) \AA$ and $c=5.423(7) \AA$. Attempts to fit the data to tetragonal $\alpha-\mathrm{U}_{3} \mathrm{O}_{7}$ and $\beta-\mathrm{U}_{3} \mathrm{O}_{7}$ systems [28] were unsuccessful.

In evaluating the structural results for the second phase formed at $250{ }^{\circ} \mathrm{C}$, preference is given to the $\mathrm{NpH}_{2+\delta}$-related assignment. All reflections are precisely defined by that tetragonal system and the systematic extinctions are consistent with the $14 / \mathrm{mmm}$ symmetry reported for neptunium hydride at low temperature [25]. The observed $c / a$ ratio of 1.999 lies within the range bounded by values of 1.995 for $\mathrm{NpD}_{2.65}$ and 2.005 for $\mathrm{CeD}_{2.23}[25,29]$. Although comparison of the observed relative intensities in Table 1 with values for $\mathrm{Sm}_{3} \mathrm{H}_{7}$ [26] show good agreement and $c / a(1.433)$ is consistent with ratios for the hydride (1.420) and $\mathrm{Ca}_{2} \mathrm{YF}_{7}$ (1.426), certain anticipated reflections are not observed. 
For example, the 002 and 110 reflections should bracket or broaden the 200 line of $\mathrm{PuO}_{2}$, but their presence is not evident. A more definitive assessment of the assignment is precluded by the apparent coincidence of diffraction lines with those of the dioxide.

Evaluation of $\mathrm{X}$-ray data for the hydrolysis product obtained at $350{ }^{\circ} \mathrm{C}$ shows that it is also a mixture of oxides. The pattern for $\mathrm{PuO}_{2}$ is evident and the observed lattice parameter (5.396(2) $\AA$ ) is in good agreement with that observed for samples prepared at $250{ }^{\circ} \mathrm{C}$. The second phase is identified as b.c.c. $\alpha-\mathrm{Pu}_{2} \mathrm{O}_{3}$. The calculated lattice parameter $\left(a_{0}=11.04(2) \AA\right)$ is identical with the published value for the cubic trivalent oxide [23]. Evidence is not found for the presence of the higher oxide formed at $250{ }^{\circ} \mathrm{C}$, but the results permit identification of the weak diffraction pattern observed in one sample prepared at that temperature. The reflections coincide with the strong reflections for $\alpha-\mathrm{Pu}_{2} \mathrm{O}_{3}$ and show that the product layer formed at the lower temperature also contains the three plutonium oxide phases.

\section{Discussion}

The reaction between plutonium and water has traditionally been thought to form trivalent or tetravalent oxides (hydrate oxides) and hydrogen as follows [30]:

$$
\begin{array}{r}
\mathrm{Pu}(\mathrm{s})+\frac{3}{2} \mathrm{H}_{2} \mathrm{O}\left[3 \mathrm{H}_{2} \mathrm{O}\right](\mathrm{g}) \longrightarrow \\
\frac{1}{2} \mathrm{Pu}_{2} \mathrm{O}_{3}\left[\mathrm{Pu}(\mathrm{OH})_{3}\right](\mathrm{s})+\frac{3}{2} \mathrm{H}_{2}(\mathrm{~g}) \\
\mathrm{Pu}(\mathrm{s})+2 \mathrm{H}_{2} \mathrm{O}\left[4 \mathrm{H}_{2} \mathrm{O}\right](\mathrm{g}) \longrightarrow \\
\mathrm{PuO}_{2}\left[\mathrm{Pu}(\mathrm{OH})_{4}\right](\mathrm{s})+2 \mathrm{H}_{2}(\mathrm{~g})
\end{array}
$$

The first reaction defines the equilibrium products expected prior to complete reaction of the plutonium; coexistence of metal and $\mathrm{Pu}_{2} \mathrm{O}_{3}$ is the thermodynamic minimum state. Completion of the second reaction describes the final equilibrium state entered after all metal is consumed. Our efforts to characterize the product formed in the $200-350^{\circ} \mathrm{C}$ range show that the above equations do not correctly describe the $\mathrm{Pu}+\mathrm{H}_{2} \mathrm{O}$ reaction. The course of reaction is clearly controlled by kinetics and not thermodynamics.

Our results suggest that the hydrolysis reaction forms a temperature-dependent multilayered oxide product on the metal surface. A dioxide layer is apparently sandwiched between a layer of b.c.c. $\mathrm{Pu}_{2} \mathrm{O}_{3}$ at the metal-oxide interface and a layer of a higher oxide at the gas-solid interface. At temperatures near $250^{\circ} \mathrm{C}$, the layers of higher oxide and dioxide are relatively thick. Thus the underlying $\mathrm{Pu}_{2} \mathrm{O}_{3}$ layer may not be detected because the oxide layers are thicker than the sampling depths of both XRD ( $1 \mu \mathrm{m}$ sampling depth) and XPS (45 $\AA$ sampling depth) analyses. The trivalent oxide layer may also be relatively thin, which would preclude detection. In contrast, diffraction data for samples reacted at $350{ }^{\circ} \mathrm{C}$ suggest that the layer of $\mathrm{Pu}_{2} \mathrm{O}_{3}$ is covered by an easily penetrated thickness of $\mathrm{PuO}_{2}$ and that the higher oxide is absent. However, the presence of an extremely thin higher oxide layer is evidenced by the appearance of $\mathrm{Pu}(\mathrm{VI})$ in the $\mathrm{X}$ ray photoelectron spectrum shown in Fig. 7. The existence of a large gradient in oxygen concentration across the oxide layer is consistent with kinetic results, showing that the reaction rate is controlled by diffusion through the product.

The chemical complexity of the product layer is further evidenced by identification of plutonium hydride regions that cover a sizable fraction of the product-metal interface. Observation of hydride is somewhat surprising since its reactions with oxygen and oxygen-containing species are both thermodynamically favored and rapid. The $\mathrm{Pu}+\mathrm{H}_{2}$ reaction is also rapid, and formation of the hydride is readily understood from a kinetic perspective. At $250{ }^{\circ} \mathrm{C}$, hydriding is possible as long as metal remains and the hydrogen pressure exceeds $2.5 \times 10^{-6}$ Torr [31]. Hydriding cannot occur until sufficient hydrogen pressure is generated in the reaction vessel by the $\mathrm{Pu}+\mathrm{H}_{2} \mathrm{O}$ reaction. Thereafter, formation of hydride is apparently controlled by the rate at which hydrogen and hydrogen-containing species are able to reach the product-metal interface by diffusing through the oxide layer. As oxidation proceeds, the interface hydride apparently advances ahead of the reaction front as product hydrogen reacts with available metal. Since the amount of hydride observed in the interface is a cumulative quantity for the entire reaction, the extent of hydriding is small relative to oxidation.

Although many properties of the phase comprising the outer product layer remain undefined, all observations indicate that it is not a hydroxide or hydrated oxide. The presence of $\mathrm{OH}$-containing species is suggested by XPS analysis, but hydroxyl is a trace constituent of the product layer penetrated by photoelectrons. The absence of bulk hydroxide is indicated by the presence of a large $O 1 \mathrm{~s}$ peak characteristic of oxide. If hydroxide is a significant constituent of the phase, a well-resolved peak should be observed in the X-ray photoelectron spectrum because of the difference between the binding energies for $\mathrm{OH}^{-}$and $\mathrm{O}^{2-}$. Reference data show that the $\mathrm{O}$ 1s peak for $\mathrm{Al}(\mathrm{OH})_{3}(533.3 \mathrm{eV})$ is $2.7 \mathrm{eV}$ higher than that for $\mathrm{Al}_{2} \mathrm{O}_{3}(530.6 \mathrm{eV})$ [15]. Similar behavior is expected for the plutonium system. The absence of a hydrated oxide phase containing $\mathrm{Pu}(\mathrm{VI})$ is suggested by appearance of hydroxyl peaks at $532 \mathrm{eV}$ for all oxide samples exposed to air and by the magnitude of that peak relative to the peak at $530.1 \mathrm{eV}$. The relative areas of these peaks imply that the water-to-oxide ion 
ratio in the outer product layer is equal to or less than 1 to 4 . This ratio represents a maximum because the hydroxyl peak is apparently due to surface water that disproportionately contributes to the observed photoelectron spectrum.

Prior studies with hydroxides and hydrated compounds of plutonium indicate that they are not stable at the temperatures used in the present investigation and support the conclusion that the surface product is an oxide. Hydroxides of $\mathrm{Pu}(\mathrm{III}), \mathrm{Pu}(\mathrm{IV})$ and $\mathrm{Pu}(\mathrm{VI})$ have been prepared by precipitation of the respective ions from aqueous solution with a strong base and are poorly characterized materials [32]. $\mathrm{Pu}(\mathrm{IV})$ hydroxide reportedly decomposes to $\mathrm{PuO}_{2}$ at temperatures above $100{ }^{\circ} \mathrm{C}$. Thermogravimetric data for the precipitate obtained from a solution of $\mathrm{Pu}(\mathrm{IV})$ nitrate by Moseley and Wing [33] show that its decomposition is complete at a temperature near $250{ }^{\circ} \mathrm{C}$ with a heating rate of $2.5{ }^{\circ} \mathrm{C} \min ^{-1}$. The observed mass loss of $20.5 \%$ far exceeds the theoretical value for $\mathrm{Pu}(\mathrm{OH})_{4}(11.7$ mass\%) and shows that coprecipitation of nitrate results in a product that can be formulated as $\mathrm{Pu}(\mathrm{OH})_{3.2}\left(\mathrm{NO}_{3}\right)_{0.8}$ or $\mathrm{PuO}_{1.6}\left(\mathrm{NO}_{3}\right)_{0.8} \cdot 1.6 \mathrm{H}_{2} \mathrm{O}$. The observed thermal decomposition steps, loss of water below $250{ }^{\circ} \mathrm{C}$ and pyrolysis of nitrate near $250{ }^{\circ} \mathrm{C}$, correspond to those found during thermal analysis of $\mathrm{Pu}\left(\mathrm{NO}_{3}\right)_{4} \cdot 5 \mathrm{H}_{2} \mathrm{O}$, and Moseley and Wing conclude that the product is a hydrated oxide and not a true hydroxide.

Characterization of the product obtained by hydrolysis of plutonium metal in liquid water at $23{ }^{\circ} \mathrm{C}$ shows that anhydrous $\mathrm{PuO}_{2}$ is formed at low temperatures and unit water activity [8]. XRD, thermogravimetric-mass spectrometric and chemical analyses of the f.c.c. phase present after oxidation to $\mathrm{Pu}(\mathrm{IV})$ demonstrate that neither hydroxide nor water is a bulk constituent of the product. A small mass loss of $3.4 \%$ occurring in the $60-150{ }^{\circ} \mathrm{C}$ range during heating to $500{ }^{\circ} \mathrm{C}$ is accompanied by formation of water as an off-gas. Since the average particle dimension of the hydrolysis product (66 $\AA$ ) is in the size range corresponding to $\mathrm{PuO}_{2}$ specific surface areas in excess of $50 \mathrm{~m}^{2} \mathrm{~g}^{-1}$, this mass change is equivalent to a single $\mathrm{H}_{2} \mathrm{O}$ monolayer on the product surface. These observations imply that hydroxides and hydrated oxides are unstable relative to oxide, especially in the conditions of the present study.

The formation of other ternary or pseudoternary phases is also doubtful. The effects of reducing contaminants such as hydrogen, carbon and nitrogen in stabilizing trivalent actinide compounds such as those erroneously identified as monoxide are well known [14], but their ability to stabilize $\mathrm{Pu}(\mathrm{VI})$ seems extremely unlikely. Oxide hydrides formed by the reaction of plutonium with water are unstable above $100{ }^{\circ} \mathrm{C}$ [8]. XPS provides a sensitive analytical method for detecting all possible contaminants except hydrogen and helium.
Evidence is not found for the presence of any extraneous anions including fluoride, the only contaminant that might stabilize hexavalent plutonium.

The new phase observed in this study differs from the solid obtained by Bagnall and Laidler [34] who reacted $\mathrm{Pu}(\mathrm{IV})$ hydroxide with ozone in water at 90 ${ }^{\circ} \mathrm{C}$. Spectroscopic analysis of their product showed $\mathrm{Pu}(\mathrm{VI})$ and $\mathrm{OH}$ groups. On the basis of these results and thermogravimetric analysis, the product was identified as $\mathrm{PuO}_{3} \cdot 0.8 \mathrm{H}_{2} \mathrm{O}$ or $\mathrm{PuO}_{2}(\mathrm{OH})_{2}$. However, definitive $\mathrm{X}$-ray results could not be obtained and evidence for anhydrous $\mathrm{PuO}_{3}$ could not be found. Unlike the hydrolysis product observed in the present study, the ozone-oxidized material is fully hexavalent and includes a significant quantity of water or hydroxide.

Results of a more recent study by Nelson [35] suggest that hyperstoichiometric plutonium oxide forms during the burning of liquid plutonium droplets $(0.2-0.4 \mathrm{~mm}$ diameter) in air. Chemical analysis of products quenched after different distances of free fall following laser ignition shows a regular increase in oxygen content with reaction time until the bulk O-to-Pu ratio reaches a value near 2.0 . The incandescent spheres "explode" in all cases involving reaction times longer than that required to form dioxide. Analytical results for these products consistently show high O-to-Pu ratios (average value, $4.5 \pm 1.5$ ) and XRD data show only $\mathrm{PuO}_{2}$. However, detection of a small splitting in the f.c.c. reflections ( $c f$. Table 1) is difficult without high resolution equipment. From a chemical perspective, the reported stoichiometries are unreasonably high, but formation of an oxide composition beyond the dioxide is indicated.

Although characterization of the oxide comprising the outer product layer is hindered by the inability to obtain pure samples of the phase, a combination of XPS and XRD results provides information on stoichiometry. These data are consistent and support the formation of a mixed-valence compound formulated as $\mathrm{Pu}(\mathrm{IV})_{3-x} \mathrm{Pu}(\mathrm{VI})_{x} \mathrm{O}_{6+x}$. The XPS results establish a minimum value of $x$ near 0.5 . Definition of this stoichiometry is based on the observation that the experimental area ratio (1 to 1.9 ) for the U(IV) to U(VI) $4 \mathrm{f}_{7 / 2}$ peaks in the $\mathrm{U}_{3} \mathrm{O}_{8}$ spectrum are close to the theoretical ratio of 1 to 2 [20]. The experimental ratio of $\mathrm{Pu}(\mathrm{IV})$ to $\mathrm{Pu}(\mathrm{VI})$ was determined from $4 \mathrm{f}_{7 / 2}$ spectra by either subtracting out the $\mathrm{Pu}(\mathrm{IV})$ component using a normalized $\mathrm{Pu}(\mathrm{IV})$ spectrum or by fitting the $4 \mathrm{f}_{7 / 2}$ spectrum with two peaks by curve synthesis. The results for the two methods are within experimental error. The $\mathrm{Pu}(\mathrm{IV})$-to- $\mathrm{Pu}(\mathrm{VI})$ ratios for products prepared at $250{ }^{\circ} \mathrm{C}$ range between 3 to 1 and 5 to 1 , corresponding to oxide stoichiometries of $\mathrm{PuO}_{2.25}$ and $\mathrm{PuO}_{2.17}$ respectively. This approach assumes that the XPS method analyzes only the outer layer and does not penetrate 
to the underlying $\mathrm{PuO}_{2}$ layer. Since the outer layer thickness must exceed $100 \AA$ to give a sharp XRD pattern and the maximum escape depth for photoelectrons is on the order of $45 \AA$, contribution to the $\mathrm{Pu}(\mathrm{IV})$ intensity from the underlying $\mathrm{PuO}_{2}$ layer seems unlikely.

However use of XRD results to estimate possible $\mathrm{Pu}(\mathrm{IV})$ contribution from $\mathrm{PuO}_{2}$ to the X-ray photoelectron spectrum leads to an upper limit for the higher oxide composition. This exercise is instructive even though over-correction of the data is likely because of the greater sampling depth of diffraction analysis. Simple comparison of relative intensities for the strongest reflections of the two oxides in Table 1 indicates that about $80 \%$ of the product is dioxide. However, correction of the observed intensity ratio is necessary. In the absence of structure factor effects, multiplicity is the major determinant of diffraction intensity [36]. Application of a threefold multiplicity correction to the tetragonal intensities [37] suggests that dioxide constitutes only $40-60 \%$ of the sample. Although the $\mathrm{PuO}_{2}$ contribution to the $\mathrm{X}$-ray photoelectron spectrum is probably less than $50 \%$, re-evaluation of the composition on that basis leads to $x=0.9$. Definition of composition limits indicates that the higher oxide formed by $\mathrm{Pu}+\mathrm{H}_{2} \mathrm{O}$ at $250{ }^{\circ} \mathrm{C}$ occurs in a stoichiometry range bounded by $\mathrm{PuO}_{2.17}$ and $\mathrm{PuO}_{2.29}$. Since the correction is of questionable validity and does not substantially alter the results, preference is given to a stoichiometry near $\mathrm{PuO}_{2.2}$.

The composition range identified for the higher oxide is consistent with a structure related to $\mathrm{NpH}_{2+\delta}$. This fluorite-related phase accommodate additional anions in distorted octahedral sites and is observed for a composition range $(0.13 \leqslant \delta \leqslant 0.65)$, extending well beyond the limits defined for the oxide [25]. A remarkable feature of the structure is that the hydride molar volume decreases by less than $0.2 \%$ over this range. Although lattice parameters determined for several hydrolysis samples are invariant and imply that the oxide is stoichiometric, diffraction results may not be a sensitive indicator of composition.

Our observation of an oxide phase containing Pu(VI) stands in conflict with prior assessments and results for the $\mathrm{Pu}-\mathrm{O}$ system. On the basis of estimated thermodynamic results, Brewer [38] predicts that $\mathrm{PuO}_{2}$ is the highest stable composition. This conclusion is supported by several unsuccessful attempts to prepare higher oxides by reacting the dioxide with strong oxidants such as $\mathrm{O}_{3}, \mathrm{NO}_{2}$ and atomic oxygen [32]. However, a reassessment of thermodynamic properties suggests that a stable composition near $\mathrm{Pu}_{3} \mathrm{O}_{7}$ is reasonable. The estimation is based on a thermochemical cycle employing data for uranium and plutonium [39]. In this cycle, $\Delta G^{\circ}$ for $\mathrm{UO}_{2}$ is used to define the free energy of formation of $\mathrm{U}_{3} \mathrm{O}_{6}$. After adjustment for the presence of one $\mathrm{U}(\mathrm{VI})$ using the standard reduction potential for the acidic U(VI)-U(IV) couple, this value differs from the experimental $\Delta G^{\circ}$ for $\mathrm{U}_{3} \mathrm{O}_{7}$ by a term that combines the differences in stoichiometry and lattice energy of $\mathrm{U}_{3} \mathrm{O}_{7}$ and $\mathrm{U}_{3} \mathrm{O}_{6}$. Use of this difference (47 $\mathrm{kcal} \mathrm{mol}^{-1}$ ) in the parallel cycle for plutonium leads to an estimated $\Delta G^{\circ}$ of $-715 \mathrm{kcal} \mathrm{mol}^{-1}$ for $\mathrm{Pu}_{3} \mathrm{O}_{7}$ $\left(-238 \mathrm{kcal} \mathrm{mol}^{-1}\right.$ for $\left.\mathrm{PuO}_{2.3}\right)$ at $298 \mathrm{~K}$. The freeenergy change calculated for disproportionation of the phase into $\mathrm{PuO}_{2}$ and $\mathrm{O}_{2}$ at $25^{\circ} \mathrm{C}$ is zero. Since the combined limits of uncertainty in the reference data and of approximation in the method is several kilocalories, formation of a stable phase in the $\mathrm{PuO}_{2.2}-\mathrm{PuO}_{2.3}$ composition range is feasible. The tendency for the phase to disproportionate is expected to increase at higher temperatures.

An alternative method for approximating the free energy of formation of the higher oxide and assessing its stability is based on our observation that dioxide is converted to $\mathrm{PuO}_{2.2}$ by reaction with water vapor. The essential process is described by the following reaction:

$$
\mathrm{PuO}_{2}(\mathrm{~s})+\frac{1}{5} \mathrm{H}_{2} \mathrm{O}(\mathrm{g}) \longrightarrow \mathrm{PuO}_{2.2}(\mathrm{~s})+\frac{1}{5} \mathrm{H}_{2}(\mathrm{~g})
$$

The value of $\Delta G^{\circ}$ derived for $\mathrm{PuO}_{2.2}$ by assuming that $\Delta G^{\circ}$ is zero for eqn. (3) and employing free-energy data for $\mathrm{PuO}_{2}$ [39] and $\mathrm{H}_{2} \mathrm{O}$ [40] is $-249.5 \mathrm{kcal} \mathrm{mol}^{-1}$ at $298 \mathrm{~K}$. Although the actual $\Delta G^{\circ}$ must be more negative than this value, the free energy for $\mathrm{PuO}_{2.2}$ disproportionation obtained using this result is +11 $\mathrm{kcal} \mathrm{mol}^{-1}$ and the phase is stable at room temperature.

The appearance of the higher oxide phase is apparently not related to the kinetic anomaly observed in Fig. 2. Formation of the phase by the Ga-containing alloy is not accompanied by a perturbation in the reaction rate. However, a less pronounced rate decrease is observed in the Arrhenius results for reaction of unalloyed metal with oxygen at $150-200^{\circ} \mathrm{C}$ [12]. Although the products obtained for $\mathrm{Pu}+\mathrm{O}_{2}$ in this temperature range are not characterized, the presence of a higher oxide seems likely. Observations of the present study suggest that the $\mathrm{Pu}(\mathrm{IV})_{3-x} \mathrm{Pu}(\mathrm{VI})_{x} \mathrm{O}_{6+x}$ phase appears in a window bounded by a temperature above $200{ }^{\circ} \mathrm{C}$ and below an undefined limit in excess of $350{ }^{\circ} \mathrm{C}$. Formation of the mixed-valence oxide at low temperatures is apparently hindered by slow reaction kinetics; its existence at high temperatures is precluded by thermodynamic instability. The inability of earlier workers to obtain the higher oxide [32] is presumably a consequence of the high experimental temperatures $\left(400-1000{ }^{\circ} \mathrm{C}\right)$ used in those studies. The phase is expected to be become increasingly more stable as the temperature is lowered, but its presence may not have been observed because of a slow formation rate or 
because of an inability to resolve its diffraction pattern from that of $\mathrm{PuO}_{2}$.

The existence of a $\mathrm{Pu}(\mathrm{VI})$-containing oxide on the surface of plutonium metal shows that the course of the $\mathrm{Pu}+\mathrm{H}_{2} \mathrm{O}$ reaction is controlled by kinetic factors. The absence of chemical equilibrium is evidenced by the progressive decrease in oxygen concentration from a maximum of $\mathrm{PuO}_{2.2}$ at the gas-solid interface to $\mathrm{PuO}_{1.5}$ at the product-metal interface. This concentration gradient arises because of the slow transport of oxygen or oxygen-containing species through the product layer. The strongly reducing environment of the metal is isolated from the oxidizing environment of the gas phase by this kinetic barrier. The magnitude of the kinetic limitation presented by plutonium oxide is evidenced by the rate at which $\mathrm{Pu}$ (III) oxide is converted to $\mathrm{Pu}(\mathrm{IV})$ oxide in liquid water at room temperature $[7,8]$. The formation of $\mathrm{PuO}_{2}$ from finely divided $\mathrm{Pu}_{2} \mathrm{O}_{3}$ (less than $100 \AA$ average particle size) requires 160 days for completion.

As discussed in a prior report [8], equilibrium is not normally observed in the $\mathrm{Pu}-\mathrm{O}$ system. Phase relationships [2] and thermodynamic data [39] show that $\mathrm{Pu}_{2} \mathrm{O}_{3}$ is the only binary oxide that can exist on the surface of plutonium metal at equilibrium. Yet, $\mathrm{PuO}_{2}$ is the only oxide observed on plutonium metal in air over a wide temperature range. Once formed, the dioxide remains on the metal surface for an extended period of time in high vacuum [14], even though $\Delta G^{\circ}$ for the reduction of $\mathrm{PuO}_{2}$ to $\mathrm{Pu}_{2} \mathrm{O}_{3}$ by $\mathrm{Pu}$ is $-13.5 \mathrm{kcal} \mathrm{mol}^{-1}$ at $25{ }^{\circ} \mathrm{C}$. This reduction reaction is slow at room temperature but is enhanced by heating $[14,41]$. The formation of an additional surface oxide with a somewhat higher stoichiometry than $\mathrm{PuO}_{2}$ is a modest extension of the well-established non-equilibrium behavior of $\mathrm{Pu}-\mathrm{O}$. The slow decrease in intensity of the $429 \mathrm{eV}$ XPS peak is observed over time in vacuum as $\mathrm{Pu}(\mathrm{VI})$ is reduced and the system moves toward equilibrium.

The formation of $\mathrm{PuO}_{2.2}$ by water and other oxidants may have a large impact on storage behavior of the oxide. During the course of the $\mathrm{Pu}+\mathrm{H}_{2} \mathrm{O}$ reaction, approximately one fifth of the tetravalent plutonium in $\mathrm{PuO}_{2}$ is oxidized to the hexavalent state as described by eqn. (3). An intriguing possibility exists because an essential step of the reaction is adsorption of water on the dioxide surface. Since the dioxide strongly adsorbs water and other oxygenated species that are not removed by normal vacuum procedures, oxidation may proceed in the absence of vapor-phase water. Irreversible and progressive increases observed in the mass of a plutonium dioxide sample during repeated adsorption-desorption cycles with water are consistent with formation of the higher oxide [42]. Even though the process is probably slow at low temperatures, the higher oxide and hydrogen may form during extended storage of samples contaminated with adsorbed water, especially if the process is enhanced by energy from radioactive decay.

\section{Conclusions}

The reaction of unalloyed plutonium with water vapor in the $200-350^{\circ} \mathrm{C}$ range forms a non-equilibrium surface layer of oxide. $\mathrm{Pu}_{2} \mathrm{O}_{3}$ is the only binary oxide that can coexist with $\mathrm{Pu}$ at equilibrium. However, the product layer $5 \mu \mathrm{m}$ thick is composed of a mixed-valence oxide phase $\mathrm{Pu}(\mathrm{IV})_{3-x} \mathrm{Pu}(\mathrm{VI})_{x} \mathrm{O}_{6+x}$ with $x$ near 0.5 , formed at the gas-solid interface and covering a layer of $\mathrm{PuO}_{2}$. A layer of $\alpha-\mathrm{Pu}_{2} \mathrm{O}_{3}$ appearing between the dioxide and metal becomes an increasingly larger fraction of the product layer at high temperatures where equilibrium is more closely approached. Localized pits of plutonium hydride cover a fraction of the product-metal interface. The uniform thickness of the oxide layer is consistent with control of the oxidation rate by diffusion of reactant through the product and suggests that the kinetics are not enhanced by presence of hydride. As with the existence of $\mathrm{PuO}_{2}$ on the metal [8], the appearance of higher oxide confirms that non-equilibrium conditions are created by slow oxidation kinetics. The role played by the higher oxide in altering the kinetics of $\mathrm{Pu}+\mathrm{H}_{2} \mathrm{O}$ is uncertain.

The appearance of the mixed-valence higher oxide raises additional questions about the validity of $\mathrm{Pu}-\mathrm{O}$ phase diagrams that are based on earlier experimental observations [43-45]. Initial uncertainties arise from results reported recently for the hydrolysis of plutonium by liquid water at room temperature [8]. Quantitative measurements of $\mathrm{H}_{2}$ formation and analytical data suggest that members of the homologous series $\mathrm{Pu}_{n} \mathrm{O}_{2 n-2}$ with $n=7,9,10$ and 12 form in sequence as $\mathrm{Pu}_{2} \mathrm{O}_{3}$ is oxidized to $\mathrm{PuO}_{2}$ by water. The existence of well-known lanthanide analogs for the homologous series members indicates that they are mixed-valence oxides containing $\mathrm{Pu}(\mathrm{III})$ and $\mathrm{Pu}(\mathrm{IV})$ and having structures derived by forming ordered anion vacancies in fluorite. The results of this study imply that the $\mathrm{Pu}-\mathrm{O}$ phase diagram extends into a second regime of mixed-valence oxide containing $\mathrm{Pu}(\mathrm{IV})$ and $\mathrm{Pu}(\mathrm{VI})$ and having a structure derived by forming anion interstitials in fluorite.

A practical aspect of this study is realized in the potential impact of $\mathrm{PuO}_{2.2}$ formation on oxide storage. Pressurization of storage containers by hydrogen is usually attributed to radiolysis of organic materials near or in contact with the oxide. The chemical reaction of oxide with absorbed water provides an alternative and potentially large source of $\mathrm{H}_{2}$. A single monolayer of 
water on the surface of a typical $\left(5 \mathrm{~m}^{2} \mathrm{~g}^{-1}\right)$ oxide is capable of generating a pressure of several atmospheres in a storage container. Further studies to verify the process and define its rate at storage temperatures are needed to address this issue adequately.

Our characterization of products formed by the $\mathrm{Pu}+\mathrm{H}_{2} \mathrm{O}$ reaction at $200-350{ }^{\circ} \mathrm{C}$ shows that the hydrolysis of unalloyed plutonium proceeds by a markedly different process than anticipated. In addition to suggesting a different $\mathrm{Pu}-\mathrm{O}$ phase diagram, the findings demonstrate that plutonium chemistry is unusually complex and that our understanding of kinetic and equilibrium properties for simple actinide systems is surprisingly limited.

\section{Acknowledgments}

This work was performed under auspices of the US Department of Energy Contracts DE-AC04-76DP03533 and W-7405-ENG-36. The assistance of John Fraser in performing XRD analyses and Anthony Rafalski in performing metallographic and WDS analyses is gratefully acknowledged.

\section{References}

1 J.L. Stakebake, J. Nucl. Mater., 38 (1971) 241.

2 C.A. Colmenares, Prog. Solid State Chem., 9 (1984) 257.

3 V. Vesterberg and L. Ekbom, in W.N. Miner (ed.), Plutonium 1970 and Other Actinides, Part 1, Metallurgical Society of AIME, New York, 1970, p. 164.

4 J.B. Raynor and J.F. Sackman, in A.E. Kay and M.B. Waldron (ed.), Plutonium 1965, Chapman and Hall, London, 1967, p. 575.

5 A. Tanon and H. Bordes-Page, in A.E. Kay and M.B. Waldron (eds.), Plutonium 1965, Chapman and Hall, London, 1967, p. 603 .

6 J.L. Stakebake and L.M. Steward, J. Electrochem. Soc., 119 (1972) 730.

7 J.M. Haschke, A.E. Hodges III, G.E. Bixby and R.L. Lucas, The reaction of plutonium with water: kinetic and equilibrium behavior of binary and ternary phases in the $\mathrm{Pu}+\mathrm{O}+\mathrm{H}$ system, US DOE Rep. RFP-3416, 1983 (US Department of Energy).

8 J.M. Haschke, Hydrolysis of plutonium: plutonium-oxygen phase diagram, in L.R. Morss and J. Fuger (eds.), Transuranium Elements, American Chemical Society, Washington, DC, 1992, Chapter 40, p. 416.

9 J.L. Stakebake and M.A. Saba, J. Less-Common Met., 158 (1990) 221.

10 J.L. Stakebake, unpublished data on the reaction of plutonium with water, 1991.

11 J.L. Stakebake, Characterization of the plutonium-water: Part I. Reaction kinetics between 200 and $350{ }^{\circ} \mathrm{C}$, in L.R. Morss and J. Fuger (eds.), Transuranium Elements, American
Chemical Society, Washington, DC, 1992, Chapter 27, p. 251.

12 J.L. Stakebake, unpublished data on the oxidation of plutonium, 1991.

13 D.T. Larson and K.M. Motyl, J. Electron Spectrosc. Relat. Phenom., 50 (1990) 67.

14 D.T. Larson and J.M. Haschke, Inorg. Chem., 20 (1981) 1945.

15 C.D. Wagner, W.M. Riggs, L.E. Davis and J.F. Moulder, in G.E. Muilenberg (ed.), Handbook of Photoelectron Spectroscopy, Perkin-Elmer Corporation, Eden Prairie, MN, 1979.

16 L.E. Cox and J.D. Farr, Phys. Rev. B, 39 (1989) 11142.

17 J.O. Willis, J.W. Ward, J.L. Smith, S.T. Kosiewicz, J.M. Haschke and A.E. Hodges III, Physica B, 130 (1985) 527.

18 D. Courteix, J. Chayrouse, L. Heintz and R. Babtist, Solid State Commun., 39 (1981) 209.

19 G.C. Allen, J.A. Crofts, M.T. Curtis and P.M. Tucker, J. Chem. Soc., Dalton Trans., (1974) 1296.

20 J. Verbist, J. Riga, J.J. Pireaux and R. Caudano, J. Electron Spectrosc. Relat. Phenom., 5 (1974) 193.

21 G.C. Allen, P.M. Tucker and J.W. Tyler, Vacuum, 32 (1982) 481.

22 J. Verbist, J. Riga, C. Tenret-Noel, J.J. Pireaux, G. d'Ursel, R. Caudano and E.G. Derouane, in H. Blank and R. Lindner (eds.), Plutonium 1975 and Other Actinides, Elsevier, New York, 1967, p. 409.

23 H. Nowotny and K. Seifert, At. Energy Rev., 4 (1) (1966) 73.

24 J.M. Haschke, A.E. Hodges III and R.L. Lucas, J. LessCommon Met., 133 (1987) 155.

25 J.W. Ward, B. Cort, J.A. Goldstone, A.C. Lawson, L.E. Cox and R.G. Haire, Electronic, structural and transport properties of (almost) rare-earth-like actinide hydrides, in L.R. Morss and J. Fuger (eds.), Transuranium Elements, American Chemical Society, Washington, DC, 1992, Chapter 39, p. 404.

26 O. Greis, P. Knappe and H. Mueller, J. Solid State Chem., 39 (1981) 49.

27 W. Gettmann and O. Greis, J. Solid State Chem., 26 (1978) 255.

28 E.F. Westrum, Jr. and F. Gronvold, J. Phys. Chem. Solids, 23 (1962) 39.

29 K. Conder, J. Schefer, E. Kaldis and C. Ru-Xiu, Z. Phys. Chem., N.F., 163 (1989) 125.

30 M.A. Thompson, in A.E. Kay and M.B. Waldron (eds.), Plutonium 1965, Chapman and Hall, London, 1967, p. 592.

31 H.E. Flotow, J.M. Haschke and S. Yamauchi, The actinide hydrides, in F.L. Oetting (ed.), The Chemical Thermodynamics of Actinide Elements and Compounds, Part 9, International Atomic Energy Agency, Vienna, 1984.

32 J.M. Cleveland, The Chemistry of Plutonium, Gordon and Breach, New York, 1970, Chapter 9.

33 J.D. Moseley and R.O. Wing, Properties of plutonium dioxide, US DOE Rep. RFP-503, 1965 (US Department of Energy).

34 K.W. Bagnall and J.B. Laidler, J. Chem. Soc., (1964) 2693.

35 L.S. Nelson, High Temp. Sci., 12 (1980) 297.

36 L.V. Azaroff and M.J. Buerger, The Powder Method in $X$ Ray Crystallography, McGraw-Hill, New York, 1958, Chapter 13.

37 M.J. Buerger, Crystal-Structure Analysis, Wiley, New York, 1960, Chapter 7.

38 L. Brewer, Chem. Rev., 52 (1953) 1.

39 L.R. Morss, Thermodynamic properties, in J.J. Katz, G.T. Seaborg and L.R. Morss (eds.), The Chemistry of the Actinide 
Elements, Vol. 2, Chapman and Hall, New York, 1986, Chapter 17.

40 D.R. Stull and H. Prophet, JANAF Thermochemical Tables, 2nd edn., in NBS Natl. Stand. Ref. Data Ser., 37 (1971).

41 K. Tereda, R.L. Meisel and M.R. Dringman, J. Nucl. Mater., 30 (1969) 340.
42 J.L. Stakebake, Hygroscopicity of plutonium dioxide, US DOE Rep. RFP-1056, 1968 (US Department of Energy).

43 T.D. Chikalla, C.E. McNeilly and R.E. Skavdahl, J. Nucl. Mater., 12 (1964) 131.

44 E.R. Gardner, T.L. Markin and R.S. Street, J. Inorg. Nucl. Chem., 27 (1965) 541.

45 H.A. Wriedt, Bull. Alloy Phase Diagr., 11 (1990) 184. 